\title{
EL CACIQUE Y EL
}

DEMONIO:

\section{CONSTRUCCIÓN Y LEGITIMACIÓN DE LA AUTORIDAD INDÍGENA EN EL MANUSCRITO DE HUAROCHIRÍ}

\section{Rauf Neme Sánchez*}

rneme@ucss.edu.pe

Universidad Católica Sedes Sapientiae

Fecha de recepción: agosto de 2017

Fecha de aceptación: diciembre de 2017

Resumen: La hipótesis de este artículo es demostrar que en el Manuscrito de Huarochiri existen estrategias discursivas que construyen y legitiman la figura de autoridad del cacique en la sociedad colonial. La lucha contra el demonio de Cristóbal Choquecasa, incluida en los capítulos 20 y 21, funciona como un relato ejemplar para la inclusión de la autoridad indígena dentro de este esquema de poder en formación. De esta manera, el Manuscrito de Huarochirí busca, como parte de su estrategia textual, legitimar el poder de estas autoridades mediante la asimilación del pensamiento hegemónico dominante que supone la campaña de la Iglesia para la extirpación de las idolatrías.

* Rauf Neme Sánchez estudia el magíster de Literatura Hispanoamericana en la Pontificia Universidad Católica del Perú. Es miembro asociado de la Asociación Peruana de Literatura Comparada (ASPLIC) y del International Comparative Literature Association (ICLA). Ha sido miembro del comité organizador y participante en los coloquios internacionales de Literatura Comparada organizados por el ASPLIC en los años 2004, 2005, 2008 y 2010. También participó como ponente en el 19. Deutscher Hispanistentag en la Universität Münster, Alemania, en el año 2013. En otras actividades, ha musicalizado el cortometrajedocumental The Calm de Fernando Vílchez, selección oficial en el festival de cine de Berlín a mejor cortometraje y ganador del XV Festival de Cine de Lima en la categoría de mejor corto-documental. 
Palabras clave: Manuscrito de Huarochirí, poder, legitimación, sociedad indiana, demonio, idolatría, Cristóbal Choquecasa.

\title{
THE CACIQUE AND THE DEMONE CONSTRUCTION AND LEGITIMATION OF INDIGENOUS AUTHORITY IN THE HUAROCHIRÍ MANUSCRIPT
}

\begin{abstract}
The hypothesis of this article is to demonstrate that in the Huarochiri Manuscript exist discursive strategies that serve to construct and to legitimize the figure of authority of the cacique in the colonial society. Therefore, the story of Cristobal Choquecasa and his fight against the devil, included in chapters 20 and 21, serve as an example for the inclusion of the indigenous authority within this scheme of power in formation. In this way, the Huarochiri Manuscript seeks, as part of its textual strategy, to legitimize the power of these new authorities through the assimilation of the dominant hegemonic thinking that supposes the campaign of the Church for the extirpation of idolatries.
\end{abstract}

Keywords: Huarochirí Manuscript, power, legitimation, indigenous society, devil, idolatry, Cristobal Choquecasa.

\section{Introducción}

a campaña de evangelización en el Nuevo Mundo representó para España cumplir con
una misión providencial dentro del clima de la Contrarreforma: era necesario propagar la fe entre los indígenas y asumir un rol tutelar frente a la ignorancia y peligrosidad de sus cultos. Así, para la mentalidad del colonizador español, sea el clero o la soldadesca, los cultos autóctonos solo podían ser explicados desde su diabolización. Al respecto, Pierre Duviols señala que los colonizadores del Perú poseían, sin distingo de su condición intelectual, un conocimiento uniforme y homogéneo sobre el demonio y sus manifestaciones. Por ello, el demonio representaba para los primeros evangelizadores y cronistas "el verdadero y único principio anímico de la religión indígena” (1977, p. 25). Estas condiciones construyen el 
marco que servirá para la introducción del diablo en el mundo andino y, en especial, en un texto singular como el Manuscrito de Huarochirí.

\section{Sobre el Texto}

Según Gerald Taylor (1987), la función principal del Manuscrito de Huarochirí era $\checkmark$ principalmente recopilar la relación de dioses de varias comunidades asentadas en la zona del mismo nombre. El propósito de la redacción del manuscrito apuntaba a rememorar la tradición histórica de los antepasados de los hombres de Huarochirí. Del mismo modo, buscaba servir a los intereses del extirpador de idolatrías Francisco de Ávila, quien lo envió a redactar.

La atribución de la autoría hasta el momento es un tema abierto, está en discusión si fue un autor único o si participaron varias personas en su redacción, o también hasta qué punto es posible rastrear la oralidad de los informantes y en qué medida el autor que organiza el material interviene en el texto. De acuerdo con la hipótesis de Gerald Taylor, el posible autor del Manuscrito de Huarochirí debía ser un indígena con un conocimiento de crónicas, pues intenta trasladar de manera coherente y sistemática la tradición histórica y prestigiosa de sus antepasados imitando el modelo del pasado heroico de los españoles. Además, Taylor admite la posibilidad de que el autor sea un indio ladino, conocedor de la lengua general, la cual era empleada en los catecismos y sermones que circularon luego del Tercer Concilio Limense, y cuya marca distintiva era su artificialidad (Estenssoro, 2003).

Sin embargo, el análisis de la situación del enunciador plantea una nueva manera de ubicar al posible autor del manuscrito. En ese sentido, las recientes investigaciones de Alan Durston (2014) y José Carlos de la Puente Luna (2015) observan la posible formación legal que ostentaría el enunciador. Así, estos investigadores se inclinan a pensar que la probable autoría del Manuscrito de Huarochirí recaería en el litigante Cristóbal Choquecasa, notable indígena que ingresa al conjunto de historias del manuscrito en los capítulos $20 \mathrm{y}$ 21 convertido en un personaje que lucha contra el demonio.

Nuestro ensayo examina el relato ejemplar de Cristóbal Choquecasa con el propósito de demostrar que el enunciador, al interrumpir la uniformidad de su relación de las divinidades de Huarochirí, introduce un elemento de negociación mediante una historia que sigue el modelo hagiográfico. Esta estrategia textual le servirá para construir 
la autoridad del indígena converso como sujeto plenamente asimilado dentro del esquema de poder. Asimismo, le ayudará a revestirle de legitimidad como interlocutor válido de las expectativas de una comunidad que buscaba también demostrar la histórica posesión de sus tierras dentro del contexto de la narración de las hazañas de sus deidades tutelares.

\section{El Lenguaje del Extirpador: el Tercer Concilio Limense, la Doctrina Christiana y el Enunciador del Manuscrito de Huarochirí}

1 Manuscrito fue redactado para servir a la campaña emprendida por el doctor Francisco
de Ávila, quien había asumido con convicción la extirpación de las idolatrías en su función de visitador. Según Antonio Acosta (1987), los pueblos de San Damián, San Pedro de Mama, San Pedro de Casta, Santa María de Jesús de Huarochirí y San Lorenzo de Quinti fueron visitados por el doctrinero, pero es a partir de 1608 que encarga la recopilación de las idolatrías que se practicaban en estas comunidades andinas, ya que había descubierto que seguían realizándose en la clandestinidad o aprovechando las fechas cristianas (Duviols, 1977).

Durante el tiempo de la redacción del texto, las disposiciones realizadas por el Tercer Concilio Limense (1582-1583) y el catecismo de la Doctrina Christiana generaban tensiones en el mundo colonial andino, las cuales también se perciben en el propio Manuscrito. En primer lugar, el Tercer Concilio buscó formas más efectivas para reprimir las prácticas de los hechiceros indígenas o el culto a escondidas que realizaban los indios a sus respectivas huacas. Así, el capítulo 42 de la segunda acción declara que "los hechiceros y ministros abominables del demonio [sean apartados para que dejen de] "inficionar a los demás indios" ([1582-1583]1982, p. 80); el capítulo 37 de su tercera acción prohíbe a los indios el acceso a los quipus pues estos “(...) conservan la memoria de su antigua superstición y ritos y ceremonias y costumbres perversas (...)” ([1582-1583] 1982, p. 103); la segunda parte del sumario establece en sus capítulos finales los castigos a los indios que fingen celebrar fiestas de cristianos, pero realizan otros ritos (cap. 95); la destrucción de las huacas, ídolos y adoratorios de caminos (caps. 96, 98 y 99); la prohibición de enterrar los cuerpos con comidas o bebidas (cap. 102), de realizar borracheras y taquies, y ofrecer sacrificios en honra del diablo al tiempo de sembrar (cap. 104); y "la extirpación de las 
demás supersticiones y ceremonias y ritos diabólicos que tiene innumerables los indios, mayormente para tomar agüero de negocios que comienzan, y en hazer mil ceremonias en los entierros de sus difuntos" (cap. 105).

En segundo lugar, la Doctrina Christiana y catecismo para instrucción de los indios, $y$ de las demás personas que han de ser enseñadas en nuestra santa fe (1584) mostró una rígida posición frente a los ritos y cultos que practicaban los indígenas:

(...) Dios es Padre, Hijo y Espíritu Santo, tres Personas y un solo Dios verdadero, y fuera de este Dios no hay otro Dios verdadero, pues lo que adoran las otras gentes fuera de los cristianos no son dioses sino demonios o engaños de hombres (...). ([1584] 1984, p. 62; el énfasis es nuestro)

Para lograr sus objetivos, la Doctrina Christiana fijó la traducción al quechua de la palabra demonio. El lexema elegido fue "supay" que para los evangelizadores presentaba características análogas al diablo europeo. Sin embargo, tanto Duviols, Taylor y Estenssoro coinciden en que la visión demonológica de los colonizadores creó un concepto que no se ajustaba exactamente a las creencias de los indios. Para Taylor, los ritos y tradiciones del Manuscrito demuestran que a pesar de que el enunciador del texto se adhiere a la misma visión demonológica del extirpador, se perciben ambigüedades en su posición que permiten la filtración de espacios de resistencia que buscan preservar las categorías de la mentalidad indígena.

Según Juan Carlos Estenssoro, la palabra sufrió un proceso de "diabolización” que le permitió perdurar, pero asimismo perdió su base humana y se convirtió en un "diablo espiritual" (2003, p. 108). En ese sentido, los evangelizadores tuvieron que resemantizar esta categoría del mundo indígena para poder apropiarse de su significado e imponer su visión en el proceso de dominación de las nuevas tierras. Para Manuel Marzal, esto demuestra que la representación del demonio en el discurso colonial poseía una doble dimensión. Por un lado, era un "hecho teológico" pues formaba parte de la afirmación de la doctrina católica y, por otro lado, era un "hecho ideológico", en el sentido de que para el colonizador las religiones indígenas representaban una parodia diabólica del cristianismo y que todos los males estaban asociados con la presencia del demonio, con lo que se justificaba la dominación colonial y el esclavismo (Marzal, 1983, p. 213). 


\section{El Cacique Converso: el Discurso Religioso-Legal del Autor del Manuscrito de Huarochirí}

Ade Cristóbal Choquecasa, un indio converso que lucha contra el demonio, podría funcionar discursivamente para construir esta posición de poder. Este personaje tiene su respectiva correlación histórica con el hijo de un curaca y ayudante del doctor Ávila (Acosta, 1984). Según Alan Durston y José de la Puente Luna, este indio litigante pudo ser el autor del propio Manuscrito. Existen varios elementos que conducen a pensar que Choquecasa cumplió un rol activo y fundamental en la preparación del texto, pues su padre Gerónimo Cancho Guaman, curaca de San Damián, formó parte del largo litigio que enfrentaba a las comunidades de Yaucha y Picoy, contexto en el que se enmarca la elaboración de este documento.

Por otro lado, es de consenso que en el Manuscrito hay un subtexto en el que predomina un discurso legal que versa sobre el derecho de posesión de tierras mediante la correlativa genealogía de deidades protectoras de las comunidades. Este conocimiento jurídico implica necesariamente la participación de un enunciador instruido en el lenguaje del derecho y capaz de poder expresar sus pretensiones a un nivel simbólico como se deduce de la estructuración del Manuscrito. Sin embargo, es difícil aún asegurar la autoría exclusiva de Choquecasa en la redacción del texto, por la forma en cómo ha llegado hasta nosotros el Manuscrito; aunque sí sería posible reconstruir o problematizar los intereses que están en juego en la inclusión de la historia de un indio notable que lucha contra el demonio. En ese sentido, el análisis del relato de Cristóbal Choquecasa, en los capítulos 20 y 21, nos permite identificar las estrategias textuales que empleó el enunciador para revestir a este indígena converso de autoridad y legitimidad.

\section{El Modelo Hagiográfico como Fuente del Relato de Cristóbal} Choquecasa

$\mathrm{C}_{\text {permite especular que tenía conocimiento de las formas narrativas que utilizaban los }}^{\text {contacto permanente del autor con el lenguaje de la doctrina y de los catecismos }}$ 
predicadores. Estas, de modo más preciso, servirían para instruir a los indios en materia de fe. Una de estas formas era el relato de corte hagiográfico.

Sobre la importancia de la hagiografía en los manuales de predicación, Manuel Pérez señaló que los relatos hagiográficos:

(...) fueron desde los primeros tiempos del cristianismo fuentes privilegiadas de historias ejemplares, pues las vidas de santos constituían el paradigma por excelencia, el mejor modo de vida a imitar en cualquier circunstancia, a excepción por supuesto de la vida de Cristo. (2011, p. 126)

La naturaleza de estas historias extraídas de ejemplos bíblicos, de pláticas religiosas de eventos del pasado de una comunidad servían como forma de prueba del poder de Dios y como un "modo completo de pensamiento y de aprendizaje, donde buena parte de los conocimientos buenos y malos se aprenderían vía la observación” (Pérez, 2011, p. 130). Siguiendo este modelo de instrucción, las poblaciones colonizadas debían asumir los nuevos códigos y valores de la religión, aún si no los entendieran bien, y desterrar lo que a los ojos del español era la causa de su desgracia: su idolatría.

Para Manuel Pérez, la hagiografía dentro del discurso evangelizador se asumía como una prueba retórica, que incluía determinadas condiciones para generar un efecto en el receptor. El relato hagiográfico constaba de cuatro elementos ineludibles: el personaje ejemplar, la presencia sobrenatural, el elemento milagroso y la intervención de la divinidad. La suma de estos cuatro elementos confirmaba su verosimilitud y su eficacia en el adoctrinamiento del público al que iba dirigido. Estos cuatro elementos - y condicionesse reúnen en el relato de Cristóbal Choquecasa, pero sus motivos se actualizan ya que su fin no es otro sino la legitimación religiosa de la sociedad indígena que acepta la nueva doctrina.

En el modelo hagiográfico tradicional, el personaje ejemplar era por lo general un santo, un mártir o algún personaje histórico de la gentilidad que servía para probar una verdad dogmática. En el caso del Manuscrito, estamos frente a un personaje que pertenece a la actualidad del propio enunciador: “(...) don Cristóbal de quien ya hablamos, vive todavía” (Taylor, 2008, p. 93). La utilización del presente puede sugerir la necesidad del enunciador para construir la verosimilitud de los hechos narrados como una prueba de fe, 
lo cual también se corrobora cuando se pretende demostrar la veracidad de la narración mediante las garantías que da el lenguaje religioso y legal: "Antes de narrarlo, don Cristóbal hizo juramento sobre la cruz" (2008, p. 93).

Para la construcción modélica del personaje, es necesario dotarle de las atribuciones que cualquier santo ostentaría: ser un personaje digno de imitación, representar el alcance de una perfección moral y espiritual y, por ende, ser digno de admiración (Pérez, 2011). El personaje de Cristóbal Choquecasa no es precisamente un representante religioso, pero sí un hombre de fe y su lucha contra el demonio puede ser entendida como un modelo de prestigio que había que reproducir. Si bien no es capaz de ejecutar milagros, tampoco el santo estaba en la condición de reproducirlos por sí mismo, ya que el "milagro hagiográfico solo se proponía para suscitar la alabanza del poder de Dios” (Pérez, 2011, p. 135). Así, el modelo le permite al enunciador del Manuscrito demostrar la omnipotencia de Dios a través de un personaje que se servirá de las armas de la religión cristiana, la oración y la cruz, para salir airoso de su enfrentamiento con el demonio: "Así, don Cristóbal adoró a Dios, nuestro señor, gritando muy fuerte todas las oraciones que sabía, y recitó repetidas veces la doctrina desde el comienzo hasta el fin" (Taylor, 2008, p. 93).

A ello hay que sumar que la lucha de Choquecasa contra el demonio está precedida por un hecho familiar que sirve para enfatizar el dramatismo de su combate. Su padre, don Gerónimo Cancho Guaman, fue un principal del pueblo que, según la información recogida por el enunciador:

(...) vivía desde pequeño muy correctamente puesto que (...) también aborrecía a estos huacas. Sin embargo, al momento de morir, engañado por el demonio, cayó en este pecado de la idolatría y, engañado por varios hombres ancianos y diabólicos, cuando estaba a punto de morir, se confesó según los ritos gentílicos. (Taylor, 2008, p. 93)

Según la doctrina, la idolatría cometida por el padre de Choquecasa inevitablemente lo condena: "Nuestro Señor Dios sabrá dónde se encuentra ahora" (p. 93) y el relato repetirá de un modo cíclico el engaño del demonio sobre el heredero de Cancho Guaman, pero que este podrá sortear y salir triunfador de él. De este modo, es posible advertir que la historia del indio converso Cristóbal funcionará como un episodio de redención que pretende 
salvar, si no el alma, el prestigio social del padre como víctima del engaño de los hechiceros, servidores del demonio.

Por otra parte, la elevación espiritual de Cristóbal Choquecasa será proporcional al adversario que deba enfrentar, en este caso la huaca Llocllayhuancupa. Este demonio es la presencia sobrenatural que el relato hagiográfico requiere y que "en las hagiografías concentraría la atención preceptiva o rectora de la Iglesia" (Pérez, 2011, p. 137). Sin embargo, para Duviols, Estenssoro y Rubina es posible notar cierta complejidad en la atribución de supay a esta huaca que aparece en varias partes del conjunto de relatos. Celia Rubina nota, por ejemplo, que hay una ambivalencia en su representación, pues la luz cegadora que se le atribuye es también marca distintiva de otras divinidades en el Manuscrito: Cuniraya cuando ilumina la tierra al mostrar su traje de oro luego de abandonar su miserable apariencia y Huatiacuri al vencer al soberbio cuñado también "cegándolo con un traje resplandeciente" (Rubina, 2015, p. 35).

Siguiendo con esta misma idea, al principio del capítulo 20, la naturaleza de Llocllayhuancupa se acerca a la de una divinidad benéfica y tutelar del pueblo checa. El enunciador narra que el huaca era hijo de Pachacamac y había sido enviado a custodiar a esa comunidad, por lo que la gente del lugar lo recibió con gran regocijo y le levantaron un santuario donde sacrificaban animales en su honor, pero al ver que con el tiempo le dejaban de adorar el huaca se retiró donde su padre. Al notar su desaparición, el pueblo fue a renovar sus ofrendas a Pachacamac y la deidad regresó. Desde entonces cuidaron con mucho celo los ritos, los cuales empezaron a ser combatidos por la llegada de Ávila y del curaca que era padre de Choquecasa. Sin embargo, al insertarse la historia de don Cristóbal — para afianzar la ejemplaridad de este personaje-, Llocllayhuancupa se reviste de todos los elementos negativos con el que la Doctrina Christiana había resemantizado la palabra supay. Así, el huaca aparece como mentiroso e infundiendo miedo.

Para vencer a este demonio, Cristóbal Choquecasa tendrá que apelar a la intervención de la divinidad, pues el milagro debe ser producto de "un acto devenido de la voluntad de Dios" (Pérez, 2011, p. 140). En ese sentido, la alusión que se hace a la Virgen María es significativa, pues revela la impronta del culto mariano en la región de Huarochirí y el conocimiento mariano que poseía el autor del Manuscrito al referir aspectos como su rol de mediadora ante el Hijo y el Padre, y su categoría de Regina: 
Ah madre, tú eres mi única madre. ¿Acaso este demonio malo me vencerá? Tú que eres mi madre, ayúdame, como una hermana, aunque soy un gran pecador, pues yo también serví a este mismo demonio. Ahora sí que sé que es un demonio. Éste no es dios, éste no podría hacer nada bueno. Tú, que eres mi única reina, sálvame de este peligro; intercede con tu hijo, mi Jesús, para que me salve de las manos de este demonio malo. (Taylor, 2008, pp. 93-95)

La intervención de la Virgen no es aislada en el Manuscrito. Tal como lo señala Maya Stanfield-Mazzi (2013), en su redacción se intercalan posibles pasajes que podrían explicar simbólicamente cómo se introdujo la devoción mariana en el mundo andino. Esto podría estar sugerido en el episodio del encargo de Cuniraya cuando el mensajero abre la taquilla en donde encuentra una imagen "de una señora muy elegante y hermosa. Su cabello era como oro crespo; estaba vestida con ropa finísima y su tamaño era minúsculo" (Taylor, 2008, p. 77). Para Stanfield-Mazzi, la figura encerrada en una caja probablemente sea de la Virgen María que evidenciaría la llegada a los Andes de las imágenes religiosas y que en el Manuscrito prefigura el posterior triunfo de la evangelización:

The text goes on to say that when the box arrives to Huayna Capac, it is opened by the huaca Cuni Raya and the world lights up with lightning. While light was a feature of Andean visions of the divine, the Spanish friars in Peru often expressed the wish that native Andeans be "alumbrados", or illuminated, by the Christian faith. [El texto continúa diciendo que cuando la caja llega a Huayna Capac, está es abierta por el huaca Cuniraya y el mundo se ilumina con relámpagos. Si bien la luz era una característica de las visiones andinas de lo divino, los frailes españoles en el Perú a menudo expresaban el deseo de que los andinos nativos fueran "alumbrados", o iluminados, por la fe cristiana]. (Stanfield-Mazzi, 2013, p. 31) ${ }^{1}$

Como el relato debe garantizar el triunfo pleno de Dios, el personaje se desplaza en dos espacios: el de la vigilia y el del sueño. Este último para la fe cristiana era el espacio predilecto del diablo pues "podía poblar de alucinaciones a sus víctimas" (Duviols, 1977,

$1 \quad$ Traducción de Sandra Villalobos Mendivil. 
p. 30). Además, un hecho significativo en el contexto de la extirpación de idolatrías es que la imaginación de los pobladores andinos era más vulnerable y podría crear fantasmas ilusorios y no pensamientos razonados (MacCormack, 2016). ¿Qué quiere demostrar el enunciador con la inclusión de este espacio que era vedado y visto con peligro por la doctrina? Creemos que quiere mostrar el triunfo de Dios en los dos niveles y sugiere que la agencia de este indígena converso garantiza simbólicamente la continuación de la evangelización:

Desde esa época hasta hoy, don Cristóbal continuó venciendo a los demás huacas de la misma manera, en sus sueños. Muchísimas veces ha vencido también a Pariacaca y a Chaupiñamca. Y a la gente le ha seguido diciendo que éstos son demonios. (Taylor, 2008, p. 99)

De esta manera, el sueño adquiere otro valor, ya no se asocia solo con el lugar del diablo, sino que se manifiesta como una verdad que es transmitida bajo la forma de oráculo, en el sentido que prefigura la continuación de la batalla contra las idolatrías. En el campo de los signos, este sueño anticipa los hechos futuros de la vida del sońante. De igual modo, indican una promesa de continuidad en la defensa de los valores de la nueva religión.

Finalmente, como señala Estenssoro, el argumento de esta lucha contra el demonio puede servir para ser "vista como una forma de ganar un acceso a un catolicismo irreprochable" (1998, p. 319), en el sentido de que el enfrentamiento de Cristóbal Choquecasa es una representación del paso de la extirpación física de los cultos a una legitimación religiosa de esta sociedad indígena que acepta la nueva doctrina. Además, su condición de hijo de cacique le permitirá cumplir con "el rol que le correspondería en tanto autoridad indígena de cambiar y multiplicar los códigos de legitimación colonial de su comunidad" (1998, p. 323). Por ello, es significativo que este relato emplee el lenguaje de los dos discursos institucionales en el mundo colonial: la religión y el derecho.

\section{Conclusión}

a inclusión de la historia de Cristóbal Choquecasa y su lucha contra Llocllayhuancupa
reproduce un modelo hagiográfico para representar la batalla continua contra las idolatrías en la región de Huarochirí. Esta lucha permite también replantear la posición 
de los indígenas en su relación con la nueva religión, y más precisamente la de la élite indígena en donde se ubica este personaje. Tal como se observa en estos dos capítulos analizados, la figura de Cristóbal Choquecasa funciona como modelo de ejemplaridad. Se aspira mediante este personaje imitar los nuevos códigos, ya que así se fortalece el proceso de evangelización y el retroceso de las prácticas idolátricas que el enunciador del Manuscrito constantemente denuncia como formas que sobreviven disfrazadas en los cultos cristianos. Por otra parte, el afianzamiento de la conversión de este indio es fundamental dentro de las posibles necesidades de prestigio y poder de esta élite en la sociedad colonial. En ese sentido, estos pasajes del Manuscrito de Huarochirí podrían funcionar como credencial de garantía para un enunciador que busca construir su autoridad como interlocutor válido y en representación de los intereses de su comunidad ante las instituciones dominantes del poder público.

\section{Referencias}

Acosta, A. (1987). Estudio biográfico sobre Francisco de Ávila. En Taylor, G., Ritos y Tradiciones de Huarochirí. Versión paleográfica, interpretación fonológica y traducción del castellano. Lima, Perú: Instituto Francés de Estudios Andinos, Instituto de Estudios Peruanos.

Doctrina Christiana. ([1584] 1984). Edición Facsimilar. Lima, Perú: Petróleos del Perú.

Durston, A. (2014). Cristóbal Choquecasa and the Making of the Huarochirí Manuscript. En Ramos, G. \& Y. Yannakis (Eds.), Indigenous Intellectuals. Knowledge, power, and colonial culture in Mexico and the Andes. Durham and London: Duke University Press.

Duviols, P. (1977). La destrucción de las religiones andinas (Conquista y Colonia). México D.F., México: Universidad Nacional Autónoma de México.

Estenssoro, J. C. (2003). Del Paganismo a la santidad. La incorporación de los indios del Perú al catolicismo 1532 - 1750. Lima, Perú: Instituto Francés de Estudios Andinos, Instituto Riva Agüero.

MacCormack, S. (2016). Religión en los Andes. Visiones e imaginación en el Perú Colonial. Arequipa, Perú: Ediciones el Lector.

Marzal, M. (1983). La transformación religiosa peruana. Lima, Perú: Fondo editorial de la Pontificia Universidad Católica del Perú. 
Pérez, M. (2011). Los cuentos del predicador. Historias y ficciones para la reforma de costumbres en la Nueva España. Navarra, España: Iberoamericana-Vervuert.

Puente Luna, J. C. de. (2015). Choquecasa va a la Audiencia: cronistas, litigantes y el debate sobre la autoría del manuscrito quechua de Huarochirí. Histórica, 39(1), pp.139158.

Rubina, C. \& Kanashiro, L. (Eds.). (2015). El Perú a través de sus discursos. Oralidad, textos e imágenes desde una perspectiva semiótica. Lima, Perú: Fondo Editorial de la Pontificia Universidad Católica del Perú.

Stanfield-Mazzi, M. (2013). Object and Apparition. Envisioning the Christian Divine in the Colonial Andes. Tucson, Arizona: The University of Arizona Press.

Taylor, G. (1987). Ritos y Tradiciones de Huarochirí. Versión paleográfica, interpretación fonológica y traducción del castellano. Lima, Perú: Instituto Francés de Estudios Andinos, Instituto de Estudios peruanos.

Taylor, G. (2008). Ritos y Tradiciones de Huarochirí. Lima, Perú: Instituto Francés de Estudios Andinos, Instituto de Estudios Peruanos, Fondo Editorial de la Universidad Nacional Mayor de San Marcos.

Tercer Concilio Limense. ([1582-1583]1982). Edición conmemorativa del IV Centenario. Lima, Perú: Facultad de Teología Pontificia y Civil de Lima. 